\title{
Applying a Sociotechnical Framework for Improving Safety at Highway-Railroad Grade Crossings
}

\author{
Michelle Yeh and Jordan Multer \\ United States Department of Transportation \\ Volpe National Transportation Systems Center
}

\begin{abstract}
To understand drivers' decisions and actions at grade crossings, we examined human factors contributing to noncompliance at grade crossings using a sociotechnical framework. This perspective allows driver behavior at grade crossings to be examined not as individual elements but rather as a function of how each element interacts with other elements within the system. In this paper, we present a model that addresses driver decision-making at grade crossings at a systems level. We identify and describe four elements of the grade crossing system influencing driver compliance: the design of the grade crossing environment, driver characteristics, the role of organizations and management, and social and political forces. We then apply the model to identify how failure to consider safety from a systems perspective contributed to the grade crossing accident that occurred in Fox River Grove, Illinois, in 1995.
\end{abstract}

\section{INTRODUCTION}

Highway-rail grade crossing safety has significantly improved in the past decade, but accidents at grade crossings continue to concern the railroad industry. A large proportion of these accidents are attributable to driver error (Office of the Inspector General (OIG), 2004). To better understand drivers’ behavior at grade crossings, the Federal Railroad Administration (FRA) sponsored research to examine human factors contributing to noncompliance at grade crossings (see Yeh and Multer, in preparation).

Traditionally, improving safety at grade crossings focused on engineering solutions (e.g., closing a grade crossing or installing active warning devices at passive grade crossings). Risk at grade crossings was assessed on a site-by-site basis, and countermeasures implemented without consideration of how the changes would affect safety at other grade crossings along the corridor or at highway intersections near the crossing. This approach significantly improved safety. Closures of public and private grade crossing, upgrading passive crossings with active warning devices, and public education campaigns contributed to an almost $50 \%$ reduction in grade crossing accidents from 1994 through 2003 (OIG, 2004). Further improvements, however, will require a broader perspective.

A systems approach to safety offers one alternative. Consideration of the effects of behavioral, organizational, social, and cultural factors is needed, since these factors and their interactions can have important effects on compliance (Moray, 2006). A systems approach also allows the benefits of a change at one grade crossing to be measured with respect to its safety impact at other grade crossings along the corridor or at nearby intersections. For example, while closing a grade crossing through the installation of physical barriers or the removal of a roadway improves safety at that particular grade crossing, it may lead to safety concerns at other grade crossings along the corridor that see an increase in vehicular traffic as a result.

To achieve a broader perspective towards safety, we applied a sociotechnical framework, first proposed by Moray and Huey (1998) to describe the nuclear regulatory domain, to the problem of driver noncompliance at grade crossings. In this paper, we describe the components of the model and apply the model to identify failures in the system that contributed to a grade crossing accident in Fox River Grove, Illinois, in 1995.

\section{SOCIOTECHNICAL FRAMEWORK}

The sociotechnical model consists of four subsystems, shown in Figure 1. For each of these subsystems, we identified corresponding elements of the highway-railroad grade crossing domain that contribute to safety.

The innermost layer of the model represents the technical/engineering system, and comprises the physical elements of the grade crossing. In this layer, we included traffic control devices used at grade crossings, such as signs and pavement markings that indicate to the driver that a crossing is near, and active warning devices 


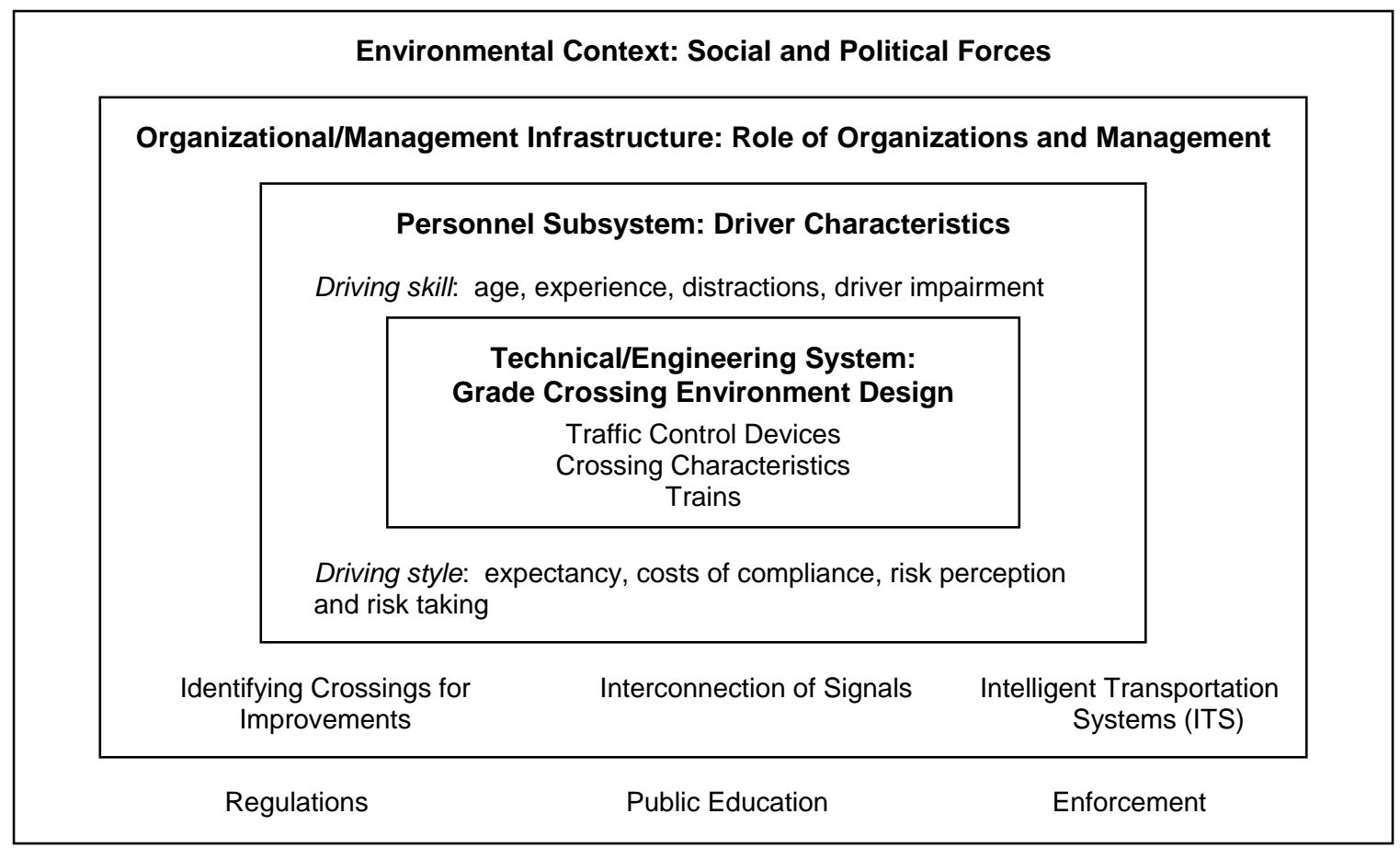

Figure 1. Four elements of the grade crossing domain.

such as flashing lights and gates that indicate the presence of a train at the crossing. Characteristics of the crossing, such as whether it is illuminated and the available sight distance, and alerting devices on the train, such as its lights, reflective markings, and its horn, are also described by this layer.

How drivers process the information from the grade crossing environment depend not only on its specific design but also on their driving skill and driving $\underline{\text { style, as represented by the next layer, the personnel }}$ subsystem. Noncompliance may be the result of error (a deficiency in skill) or intention (style). Driving skill describes characteristics of information processing that limit driver performance, for example, age, experience, distractions, and impairment due to alcohol-use or fatigue. On the other hand, driving style refers to biases and attitudes that affect how one chooses to drive. Driving style shapes one's expectancy of a train at a crossing, the perceived costs of compliance (e.g., the waiting time for a train to pass), and one's risk taking tendencies.

The third element of the model considers the role of organizations and management. Improving grade crossing safety requires coordination among agencies at the federal, state, and local levels, but this is difficult in the railroad industry where various authorities exercise jurisdiction. Railroad companies install and own the tracks and the rights-of-way (i.e., the property to either side of the tracks). They maintain the tracks, the roadway between and around the rails, and the traffic control devices at the grade crossing. Public agencies and private entities own the roadways at the grade crossing. The local municipality, county, or state maintains public crossings, and landowners maintain private crossings, which are usually located on roadways the general public does not use. Coordination between all these parties is required to identify which crossings to improve and what countermeasures to implement. It is also important to consider how to overcome institutional barriers. A highway-railroad grade crossing is a multimodal intersection, but railroad engineers tend to focus on railroad issues and highway engineers on highway issues. Poor communication between these modes contributes to problems integrating highway and rail traffic control devices due to inadequate information regarding traffic flow (e.g., interconnecting highway signals and grade crossing warning devices).

Additionally, public agencies may wish to partner with private industries to develop, implement, and test new Intelligent Transportation Systems (ITS) technologies at grade crossings.

All these elements function within a political and social context, as described by the environmental subsystem. This layer addresses the regulatory oversight and the development of policies requiring safe practices. It includes educating the public on their responsibilities at grade crossings and the enforcement of the appropriate traffic regulations. The actions of state legislatures and courts impact the effectiveness of these regulations based on how they are adjudicated. For 
example, the FRA has worked with local law authorities to implement automated photo enforcement, but judges in some states will not admit evidence collected via photo enforcement and have noted concerns about whether violators were sufficiently informed of their rights and responsibilities. Additionally, public support or opposition and the specific policies and actions of regulators will influence safety. Failure to recognize these factors can prevent the implementation of valid safety improvements or result in an ineffective implementation.

\section{MODEL CONTRIBUTIONS}

The value of examining safety using a systems perspective can be seen by applying the sociotechnical model in Figure 1 to understand factors that contributed to a grade crossing accident at Fox River Grove, Illinois, on October 25, 1995. In this accident, a commuter train struck a school bus, which was stopped for a red light at a traffic intersection 45 feet from the grade crossing. The rear of the bus extended onto the tracks, approximately three feet into the path of the train. Seven of the 35 students on the bus sustained fatal injuries, 24 students received serious injuries, and the bus driver received minor injuries.

In their investigation, the National Transportation Safety Board (NTSB) attributed the probable cause of the accident to the bus driver stopping the bus on the railroad tracks. Several other safety issues were also identified, and we consider these issues with respect to the model starting with the central layer.

The NTSB report noted that some visual and auditory cues from the grade crossing environment (described by the technical/engineering subsystem) were undetected by the bus driver and passengers. The flashing lights and gates at the crossing were activated upon the train's approach, but the bus driver could not see the activated warning lights since the front of the bus passed them. When the crossing gate descended, it struck the left side of the school bus. The passengers who saw the gate strike the bus did not initially understand the severity of their situation. Additionally, the engineer sounded the train horn, and audibility tests conducted by the NTSB indicated that the sound level of the train horn exceeded FRA requirements. However, sound attenuation inside the bus, combined with the sound of radios and conversations in the bus and the fact that the doors and windows of the bus were closed, inhibited the effectiveness of the auditory alert (NTSB, 1996, 1998). While these cues from the grade crossing environment were missed, it is unknown whether the bus driver would have reacted to these warnings had they been detected because she did not realize that the bus was in the path of the train.

The NTSB investigation also identified failures in driver training, which are addressed by the second and third layers of the model. A substitute driver, who was unfamiliar with the route, operated the bus on the day of the accident. Her expectancy upon approaching the intersection was that she needed to cross the tracks before stopping to trigger a sensor to change the light at the highway intersection from red to green. Once she drove over the tracks to wait for the light to change, she lacked awareness of the bus' position with respect to the tracks, a deficiency in driving skill addressed by the personnel subsystem. The regular bus driver who was familiar with the crossing knew from experience that there was inadequate storage space for the bus, and typically stopped before the crossing. There was no indication that the substitute bus driver attempted to determine whether there was adequate space beyond the grade crossing for the bus.

Additionally, the NTSB noted that the school district did not have a process for identifying and sharing information about potential hazards along the route, a failure in the organizational/management infrastructure. Drivers were expected to report hazards they encountered verbally or note them on a pre-trip inspection form, but this policy was not enforced. In fact, the route maps provided to drivers that the NTSB examined showed no indication of hazardous locations.

The NTSB report indicated that the most significant cause of the accident was the lack of coordination between highway and railroad agencies to ensure the adequate timing of highway and railroad signals that would have prevented vehicles from stopping on the tracks at that intersection. Post-accident testing suggested that the highway signal presented a green light for only 2 to 4 seconds before impact. This failure to coordinate the highway and railroad signals is identified in the organizational/management infrastructure, the third layer of the model. The Illinois Department of Transportation (IDOT) responded to several maintenance complaints in the nine months prior to the accident about a lack of synchronization between the warning lights at the crossing and the traffic signal at the intersection that indicated that traffic could not clear the track area properly before the approach of a train. Each complaint was investigated, with the necessary repairs made so that the timing of signals was determined to be operating normally. However, tests, conducted by the NTSB after the accident, showed that while the active warning devices at the crossing provided the minimum 20 second warning time required by the Manual on Uniform Traffic Control Devices 
before the approach of a train (FHWA, 2003), in approximately $50 \%$ of the trials, the traffic lights provided 10 seconds or less clearance time for vehicles at the highway intersection to clear the tracks. Although IDOT and the railroad exchanged documents prior to the accident about the warning times at the grade crossing, the traffic engineer who programmed the traffic signal set it based on his experience with road conditions rather than on the information provided by the railroads.

Finally, the NTSB report also noted that the state failed to take adequate measures to prevent vehicles from queuing onto the railroad tracks when stopped at the traffic intersection, a failure in the environmental layer. There is a lack of guidance regarding how to inform drivers of the amount of storage space at highway intersections near grade crossings. The available storage space at this particular intersection ranged from 28.5 feet to 21 feet (measured from the far rail to the stop line) a length insufficient to accommodate large vehicles such as trucks, tractor trailers, and buses. The short queuing area resulted when IDOT widened the roadways six years prior to the accident and used approximately 35 feet of property belonging to the railroads. At the time, the railroad expressed their safety concerns because the tracks were less than 50 feet from the intersection. However, IDOT completed their project as planned.

\section{DISCUSSION}

The Fox River Grove grade crossing accident illustrates the value of addressing safety from a systems perspective. While it is always easy to identify system failures in retrospect, the example shows how various layers of the model interact and highlights the impact that organizations can have on safety and the challenges faced in overcoming institutional barriers. This systems perspective is new to the railroad domain where safety improvements to grade crossings have traditionally used a narrow view towards risk management, focusing on individual elements of the grade crossing environment.

One example of this systems-based approach to safety is the efforts by the state of North Carolina to implement countermeasures along its Southeast High Speed Rail Corridor to reduce the overall accident risk along the corridor. The "Sealed Corridor" initiative resulted in a variety of safety improvements at grade crossings along the corridor, including crossing closures, grade separation, photo enforcement, and the use of barrier systems (e.g., four-quadrant gates and median barriers). A comparison of annual fatality rates at the crossings before and after improvements to the crossings were implemented showed that approximately five lives were saved with the improvements, and that this accident reduction rate could be sustained even as traffic volume and train speed along the corridor increased by implementing similar improvements at additional crossings along the corridor (FRA, 2002).

The FRA is beginning to apply this sociotechnical approach to address human factors issues. The model described here offers a new perspective for examining driver behavior at grade crossings. The model includes factors addressing the design of the grade crossing environment, driver performance, the actions of federal and state agencies and local municipalities, and the forces exerted by the public which can be used for selecting and implementing countermeasures to improve safety. The model offered here is descriptive in nature. While it may be of interest to quantify the contribution of each layer - and the elements within it (e.g., by assigning weights to conduct a root cause analysis after an accident), the contribution of a particular layer will vary depending on the context. The value of the model presented here is in recognizing the individual contributions of each of the four layers towards grade crossing safety and in providing a framework for describing the interaction within layers of the system.

\section{ACKNOWLEDGEMENTS}

This research was conducted with funding from the FRA's Office of Research and Development. The authors wish to thank Dr. Thomas Raslear for his direction and helpful guidance on this program and to Dr. Stephen Popkin who provided suggestions and feedback on this paper.

The views expressed herein are those of the authors and do not necessarily reflect the views of the John A. Volpe National Transportation Systems Center, the Research and Innovative Technology

Administration, or the United States Department of Transportation.

\section{REFERENCES}

Moray, N.P. and Huey, M. (1988). Human factors research and nuclear safety. Washington, D.C.: National Academy Press.

Moray, N. (2006). Culturing safety for railroads. Transportation Research Circular E-C085, Railroad Operational Safety: Status and Research Needs. Washington, D.C.: Transportation Research Board.

Federal Highway Administration (2003). Manual on Uniform Traffic Control Devices. Washington, D.C.: U.S. Department of Transportation.

Federal Railroad Administration. (2002) North Carolina 
"Sealed Corridor" Phase 1. U.S. DOT Assessment Report. Washington, D.C.: U.S. Department of Transportation.

Lerner, N., Ratte, D., and Walker, J. (1990). Driver Behavior at Rail-Highway Crossings (FHWA-SA90-008). Washington, D.C.: Federal Highway Administration, Office of Highway Safety.

National Transportation Safety Board. (1996).

Highway/Railroad accident report: Collision of Northeast Illinois Regional Commuter Railroad Corporation (METRA) Train and Transportation Joint Agreement School District 47/155 School Bus at Railroad/Highway Grade Crossing in Fox River Grove, Illinois, on October 25, 1995

(NTSB/HAR-96/02). Washington, D.C.: National Transportation Safety Board.

National Transportation Safety Board. (1998). Safety Study: Safety at Passive Grade Crossings Volume 1: Analysis (NTSB/SS-98/02). Washington, D.C.: National Transportation Safety Board.

Office of the Inspector General (2004). 2004 Audit of the Highway-Rail Grade Crossing Safety Program (Report Number: MH-2004-065). Washington, D.C.: Federal Railroad Administration.

Yeh, M., and Multer, J. (in preparation). Driver Behavior at Highway-Railroad Crossings: A Literature Review from 1990-2006. Volpe National Transportation Systems Center, U.S. Department of Transportation. 